University of Wollongong

Research Online

Australian Institute for Innovative Materials -

Papers

Australian Institute for Innovative Materials

$1-1-2018$

\title{
The effect of amorphous TiO2 in P25 on dye-sensitized solar cell performance
}

\author{
Kadhim Al-Attafi \\ University of Wollongong, kmkaa533@uowmail.edu.au \\ Andrew Nattestad \\ University of Wollongong, anattest@uow.edu.au \\ Qijie Wu \\ University of Wollongong, qw988@uowmail.edu.au \\ Yusuke Ide \\ National Institute for Materials Science, Japan \\ Yusuke Yamauchi \\ University of Wollongong, yusuke@uow.edu.au
}

See next page for additional authors

Follow this and additional works at: https://ro.uow.edu.au/aiimpapers

Part of the Engineering Commons, and the Physical Sciences and Mathematics Commons

Research Online is the open access institutional repository for the University of Wollongong. For further information contact the UOW Library: research-pubs@uow.edu.au 


\title{
The effect of amorphous TiO2 in P25 on dye-sensitized solar cell performance
}

\begin{abstract}
P25 is one of the most widely used forms of titanium(IV) oxide (TiO2), routinely utilised in dye-sensitised solar cells (DSCs), where it is often employed as a control, in spite of its poorly defined nature and the typically low device efficiency (or possibly because of this). Work by Park in 2000 and later by Lin et al. suggests that the rutile component might not be to blame for this, as has often been claimed. Recently it has been observed that P25 has quite a sizable amorphous content. A method to selectively remove this non-crystalline material has been developed, allowing for scrutiny of the role this amorphous material plays. Here we compare hydrothermally treated P25 (H-P25) with the as-received material, realizing solarto-electric conversion efficiencies of $5.3 \%$ and $3.2 \%$ respectively. More importantly, this reveals important information about the detrimental effect of amorphous TiO2 on DSC performance, with broader implications, as most researchers do not actively examine their synthesized materials for the presence of an amorphous component.
\end{abstract}

\section{Disciplines}

Engineering | Physical Sciences and Mathematics

\section{Publication Details}

Al-Attafi, K., Nattestad, A., Wu, Q., Ide, Y., Yamauchi, Y., Dou, S. Xue. \& Kim, J. (2018). The effect of amorphous TiO2 in P25 on dye-sensitized solar cell performance. Chemical Communications, 54 (4), 381-384.

\section{Authors}

Kadhim Al-Attafi, Andrew Nattestad, Qijie Wu, Yusuke Ide, Yusuke Yamauchi, Shi Xue Dou, and Jung Ho Kim 
This article was originally published as:

Al-Attafi, K., Nattestad, A., Wu, Q., Ide, Y., Yamauchi, Y., Dou, S. Xue. \& Kim, J. (2018). The effect of amorphous TiO2 in P25 on dye-sensitized solar cell performance. Chemical Communications, 54 381-384.

\section{Journal Name}

\section{COMMUNICATION}

\section{The role of amorphous material in $\mathrm{P} 25$, mixed phase $\mathrm{TiO}_{2}$, on Dye Sensitized Solar Cells performance}

Received 00th January 20xx, Accepted 00th January 20xx

DOI: $10.1039 / \times 0 \times x 00000 x$

\author{
Kadhim Al-Attafi ${ }^{a, b}$, Andrew Nattestad ${ }^{c, *}$, Qijie $W^{c}{ }^{c}$, Yusuke Ide ${ }^{d, *}$, Yusuke Yamauchi, ${ }^{a, d}$, Shi Xue \\ Dou $^{a}$ and Jung Ho Kim ${ }^{a}{ }^{*}$
}

www.rsc.org/

P25 is one of the most widely used forms of Titanium (IV) oxide $\left(\mathrm{TiO}_{2}\right)$, including being routinely employed in Dye-sensitised Solar Cells (DSCs), where it is often used as a control, in spite of its poorly defined nature and in spite of the typically low resulting device efficiencies (or possibly because of this). Work by Park and later Lin suggests that the rutile component might not be to blame for this, as has often been claimed. Recently it has been observed that P25 can contain quite a high amorphous content. A method to selectively remove this material has been developed, allowing for scrutiny of the role this amorphous material plays. Here we compare hydrothermally treated P25 (H-P25) with the as-received material, realizing $5.3 \%$ and $3.2 \%$ solar-to-electric conversion efficiencies respectively. More importantly, this reveals important information about the detrimental role of amorphous $\mathrm{TiO}_{2}$ on DSC performance, with broader implications, as most researchers do not actively examine their synthesized materials for an amorphous component.

P25 has been adopted as a cheap source of $\mathrm{TiO}_{2}$ nanoparticle and has been widely used in photocatalysis and dye-sensitized solar cells (DSCs) applications ${ }^{1,2}$. As an integral component of a DSCs, the photoanode serves as a high surface area to adsorb the sensitizer and as a medium for transferring electrons injected from the sensitizer to the charge collector, and is commonly made of $\mathrm{TiO}_{2}$ nanoparticles ${ }^{3}$. The crystal structure of $\mathrm{TiO}_{2}$ is, therefore, an important factor to be considered in designing efficient photoanodes for DSCs.

Even though P25 has been widely applied in photoanodes for $\mathrm{DSC}^{4}$, it is well known for it's comparatives poor performance.

${ }^{a}$ Institute for Superconducting and Electronic Materials (ISEM), Australian Institute for Innovative Materials (AIIM), University of Wollongong, North Wollongong, NSW 2500, Australia.Email: jhk@uow.edu.au

${ }^{b}$ Department of Physics, College of Science, University of Karbala, Karbala 56001, Iraq.

Intelligent Polymer Research Institute (IPRI), ARC Centre of Excellence for Electromaterials Science, AlIM, University of Wollongong, North Wollongong, NSW 2500, Australia. Email: annattest@uow.edu.au

World Premier International (WPI) Research Center for Materials Nanoarchitectonics (MANA), National Institute for Materials Science (NIMS) 1-1 Namiki, Tsukuba, Ibaraki 305-0044, Japan.Email: Ide.Yusuke@nims.go.jp

†Electronic Supplementary Information (ESI) available:

See DOI: $10.1039 / x 0 x x 00000 x$
This has often been attributed to the rutile component, with the conduction band edge of rutile below that of anatase phase by $\sim 0.2 \mathrm{~V}$. As a first approximation, this could be expected to affect the open circuit value $\left(V_{o c}\right)$, anatase is usually the preferred form of $\mathrm{TiO}_{2}$, with record efficiencies all attained using this crystal phase ${ }^{5,6}$. It has however been seen that DSCs based on rutile photoanodes, display similar $\left(V_{o c}\right)$ and fill factors (FF) as those using anatase $\mathrm{TiO}_{2}$. Short circuit current densities $\left(J_{s c}\right)$ of rutile based devices are however typically lower ${ }^{7,8}$, with Park reporting DSCs based on a rutile photoanodes having $J_{s c}$ values around $70 \%$ of devices based on anatase photoanode. This was attributed to the lower dye loading in the rutile sample. More recently, our group reported the application of high surface area, hierarchically assembled, 3D rutile nanorod assemblies as photoanodes for DSC, utilizing a high extinction coefficient organic dye (D149) to realize the similar performance compared to anatase photoanodes with the similar total surface area (5.5\% versus $5.8 \%$ efficiency). The difference in $\left(J_{s c}\right)$ here was only $13 \%$ with FF and $V_{o c}$ again close to one another ${ }^{8}$. In light of these studies which suggest that solar-to-electric conversion efficiency is not inherently low for rutile based DSCs, the question remains as to why P25 shows such poor performance in DSCs. Some studies have shown that the electronic structure of amorphous $\mathrm{TiO}_{2}$ is similar to that of anatase and rutile phases ${ }^{9,10}$. On the other hand, amorphous $\mathrm{TiO}_{2}$ has localized trap states near both the valance and conduction band edges, due to disordered positions of $O$ and $\mathrm{Ti}$ atoms, resulting from a network distortion ${ }^{9,10}$. Studies have also shown that the adsorption of dye molecules on $\mathrm{TiO}_{2}$ surfaces is strongly correlated with surface facets. The particles without well-defined facets are more likely to show worse surface dye packing, resulting in exposed surface, which is susceptible to charge recombination reactions ${ }^{11-13}$. Faceted surfaces can also enhance light scattering which again contributes to improving light harvesting efficiency ${ }^{14}$. It is seen the amorphous $\mathrm{TiO}_{2}$, will have low dye packing density ${ }^{15,16}$. Thus, it is speculated that removing this amorphous $\mathrm{TiO}_{2}$ will improve DSC performance. 
Recently, our group observed substantial amorphous content in P25 nanoparticles (which cannot be seen directly from XRD diffraction patterns). A hydrothermal treatment process was developed to remove this amorphous material by selective dissolution and recrystallization ${ }^{17}$. This modified $\mathrm{TiO}_{2}$ material showed remarkably enhanced charge separation and photocatalytic efficiency ${ }^{17}$ due to the removal of recombination sites/barriers for charge separation. Getting rid of this amorphous content, while maintaining the high surface area, is, however, a challenge which needs to be considered. In another study, Kurian used a water treatment to convert an amorphous $\mathrm{TiO}_{2}$ layer $(15 \mathrm{~nm})$, deposited by atomic layer deposition, to crystalline anatase nanoparticles, which results in improving the electron transport in $\mathrm{TiO}_{2}$ nanotubes. These were then used as photoanode in a DSC $^{18}$ (PCE was enhanced $25 \%(3.9 \%$ and $4.9 \%$ for untreated and treated photoanode respectively)).

Herein, we apply the recently developed amorphous content free analogue of P25 (H-P25) in a photoanode to investigate the role amorphous $\mathrm{TiO}_{2}$ plays on DSC performance, through comparison with devices based on P25. Significantly, DSC device based on (H-P25), sensitized with N719, showed a power conversion efficiency PCE of $5.3 \%$, compared to $3.2 \%$ for the untreated P25 photoanode.

Transmission electron microscope (TEM) images showed that the primary particle size and shape of $\mathrm{H}-\mathrm{P} 25$ were similar to those of P25 (Figure. 1a and b). On the other hand, H-P25 had a large number of extended interfaces compared to P25, as shown by the yellows arrows in Figures $1 \mathrm{a}$ and b. TEM and HRTEM (Figure. $1 \mathrm{c}$ and d) shows that the amorphous content removed during the hydrothermal treatment was converted to crystalline material. The surface area of $\mathrm{H}-\mathrm{P} 25$, obtained from nitrogen isotherm measurements, is around $20 \%$ lower than that of P25 $\left(47 \mathrm{~m}^{2} \mathrm{~g}^{-1}\right.$, as compared to $57 \mathrm{~m}^{2} \mathrm{~g}^{-1}$, shown in Figure $1 \mathrm{e}$ and Table 1). The lower surface area of H-P25 can be attributed to increased interparticle contact and a greater degree of agglomeration resulting from the re-deposition of dissolved amorphous $\mathrm{TiO}_{2}$. The inset in Figure $1 \mathrm{e}$ shows that the pore size distribution of H-P25 is significantly changed after removal of the amorphous content, with the average size being substantially larger than that of P25. This leads to higher surface roughness and slightly lower porosity than P25 (Table 1). XRD analysis showed that diffraction peaks related to anatase and rutile in H-P25 were more intense, indicating higher crystallinity, than for P25 (Figure 1f). Meanwhile, the compositional analysis reported previously showed P25 to be (76 wt\% anatase:13 wt\% rutile:11 wt\% amorphous) and H-P25 to be $(81: 19: 0)^{17}$.

Table 1: Porosity (P), Specific surface area (SA) and Surface roughness factor (RF) data of $\mathrm{P} 25$ and H-P25.

\begin{tabular}{cccc}
\hline Samples & $\begin{array}{c}\text { Porosity } \\
(\%)^{\mathrm{a}}\end{array}$ & $\begin{array}{c}\text { Specific surface area } \\
\left(\mathrm{m}^{2} \mathrm{~g}^{-1}\right)\end{array}$ & $\begin{array}{c}\text { Roughness } \\
\left(\mu \mathrm{m}^{-1}\right)^{\mathrm{b}}\end{array}$ \\
\hline P25 & 71 & 57 & 70.1 \\
H-P25 & 63 & 47 & 75.5 \\
\hline
\end{tabular}

a porosity calculated as $\mathrm{P}=\mathrm{P}_{\mathrm{v}} /\left(\rho^{-1}+\mathrm{P}_{\mathrm{v}}\right)$, where $\mathrm{P}_{\mathrm{v}}$ is the cumulative pore volume $\left(\mathrm{cm}^{3} \mathrm{~g}^{-1}\right)$, and $\rho^{-1}$ is the inverse of the density of P25 and H-P25 $\left(\rho^{-1}=0.23 \mathrm{~cm}^{3} \mathrm{~g}^{-1}\right.$ and $0.26 \mathrm{~cm}^{3} \mathrm{~g}^{-1}$ respectively). ${ }^{b}$ the value of the surface roughness factor $\left(R_{F}\right)$ is estimated as $R_{F}=\rho(1-P) S_{A}{ }^{19}$.

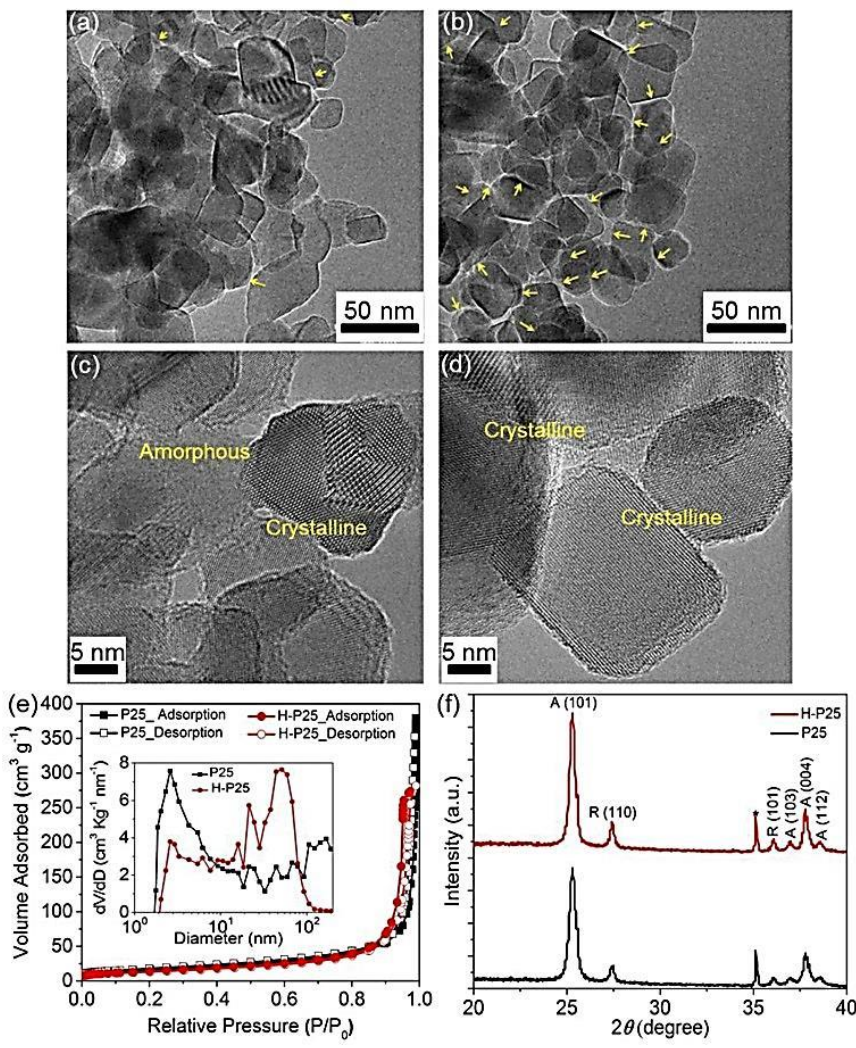

Figure 1: TEM images (a) and (b) and HTEM images (c) and (d) of P25 and H-P25 respectively; (e) $\mathrm{N}_{2}$ adsorption/desorption isotherms; (f) XRD patterns. $\left({ }^{*}\right)$ indicates the diffraction peak of $\mathrm{Al}_{2} \mathrm{O}_{3}$, used as a standard for XRD normalization.

The current-voltage responses of DSC devices based on either H-P25 or P25 photoanodes are plotted and shown in Figure $2 \mathrm{a}$. The key photovoltaic parameters, as well as the amount of adsorbed dye, are given in Table 2. DSCs incorporating H-P25 photoanodes exhibited photocurrent conversion efficiencies of $5.3 \pm 0.5 \%$, substantially higher than those of the P25 based devices $3.2 \pm 0.3 \%$ (Table1 $\mathrm{SI}$ ). The higher performance is mainly due to improvement in fill factor (FF) with some increase in $J_{s c}$. The $V_{o c}$ remained consistent between the two sets devices. $J_{s c}$ enhancements were further investigated by incident photon to current conversion efficiencies (IPCE) measurements (Figure. 2b). The IPCE of H-P25 based devices is higher than that of P25 over the range $400-725 \mathrm{~nm}$, consistent with the higher value of $J_{s c}$ and PCE which results from the fact that the sensitized $\mathrm{H}-\mathrm{P} 25$ could harvest more light in this range than that of sensitized P25. It is therefore, H-P25 has higher IPCE due to higher dye loading resulting in enhancing the light harvesting efficiency and thereby increasing the photocurrent value. The higher $J_{s c}$ attained from H-P25 devices can be attributed to better light harvesting, in spite of the materials lower specific surface area, which is explained substantially higher packing density of these dyes on H-P25 than P25 (30 \pm 1 and $\left.24 \pm 1 \mathrm{nmol} . \mathrm{cm}^{-2}\right)$ and $\left(61 \pm 1.5\right.$ and $\left.48 \pm 2.3 \mu \mathrm{mol} . \mathrm{cm}^{-3}\right)$ respectively, quantified using a desorption method to compare 
the light harvesting efficiency for both photoanodes (Table S2 and Figure S1). This higher density of dyes is attributed to more favorable sites for dye binding on faceted surfaces, as opposed to amorphous (see Scheme 1). As the main difference in the observed photovoltaic responses related to $\mathrm{FF}$, Electrochemical Impedance Spectroscopy (EIS) was employed. EIS measurements were carried out under 1 sun illumination, to compare electron transfer rates and lifetimes, with Nyquist and Bode plots shown in Figure $2 \mathrm{c}$ and $2 \mathrm{~d}$ respectively. These were analyzed based on the model proposed by Bisquert and co-workers ${ }^{20,21}$. Parameters from fitted data are shown in Table 3, with $R_{s}$ referring to the series resistance, $R_{c t 1}$ and $R_{c t 2}$ to charge transfer resistance at the counter and in the working electrode respectively. $\mathrm{CPE}_{1}$ and $\mathrm{CPE}_{2}$ represent the constant phase elements associated with the counter and working electrodes respectively. CPE is used in this EIS model instead of a simple capacitor as interfaces between the electrolyte/photoanode, and electrolyte/counter electrode, which form double layer capacitance, are not an ideal due to the diffuse electrolyte layer (leaky capacitor), the surface roughness of electrodes and non-uniform current distribution ${ }^{21}$. Two semicircles were observed in Nyquist plots, as seen in Figure 2c, which were fitted (Figure. S2) using an equivalent circuit shown in the inset. The first semicircle originated from higher frequencies and represents the electrochemical impedance from electron transfer at the counter electrode/electrolyte interface. As expected these were very similar for both devices tested. Meanwhile, the second semicircle at (mid-range frequencies) is related to the impedance of the interface between the photoanode material and liquid electrolyte in competition with the transfer of injected electrons through photoanode material ${ }^{20,22}$.

Devices based on H-P25 have a lower electrochemical impedance at electrolyte $/ \mathrm{TiO}_{2}$ interface $\left(36.5 \Omega . \mathrm{cm}^{-2}\right)$ compared to those of P25 photoanodes $\left(45 \Omega . \mathrm{cm}^{-2}\right.$ ) which indicates reduced electron recombination. As shown in Fig. $2 \mathrm{~d}$, frequencies of the local impedance maxima ( $f_{\text {max }}$, low frequencies) in the devices were $79 \mathrm{~Hz}$ and $100 \mathrm{~Hz}$ respectively. The electron lifetime, calculated using $\tau_{n}$ $=1 / 2 \pi f_{\max }{ }^{23}$, in $\mathrm{H}-\mathrm{P} 25$ based cells is therefore seen to be longer than that in the P25 based photoanode, again indicating that electron recombination losses have been mitigated, increasing the devices FF. Furthermore, devices based on H-P25 have higher chemical capacitance $\left(C_{\mu}\right)$ value compared to P25, indicating higher densities of shallow traps that receive more electrons generated from the exciting dye (higher electron density $)^{8}$. It is postulated that the amorphous material may form electronic barriers ${ }^{15,24}$.

Table 2: Photovoltaic parameters and the amount of dye loading of H-P25 and P25 photoanodes based DSC

\begin{tabular}{ccccc}
\hline Devices & $J_{s c}\left(\mathrm{~mA} \cdot \mathrm{cm}^{-2}\right)$ & $V_{o c}(\mathrm{~V})$ & $\mathrm{FF}(\%)$ & PCE (\%) \\
\hline P25 & $10.2 \pm 0.3$ & $0.76 \pm 0.04$ & $55 \pm 2$ & $3.2 \pm 0.3$ \\
H-P25 & $11.5 \pm 0.2$ & $0.80 \pm 0.03$ & $67 \pm 5$ & $5.3 \pm 0.5$ \\
\hline
\end{tabular}

Table 3: Electrochemical impedance data of devices based on H-P25 and P25 photoanodes.

\begin{tabular}{ccccc}
\hline Devices & $\begin{array}{c}\mathrm{R}_{\mathrm{s}} \\
\left(\Omega . \mathrm{cm}^{-2}\right)\end{array}$ & $\begin{array}{c}\mathrm{R}_{\mathrm{ct} 1} \\
\left(\Omega . \mathrm{cm}^{-2}\right)\end{array}$ & $\begin{array}{c}\mathrm{R}_{\mathrm{ct} 2} \\
\left(\Omega . \mathrm{cm}^{-2}\right)\end{array}$ & $\begin{array}{c}\mathrm{C} \mu \\
\left(\mu \mathrm{F} . \mathrm{m}^{-1}\right)\end{array}$ \\
\hline P25 & $6.1 \pm 0.2$ & $10 \pm 0.6$ & $45 \pm 0.7$ & $112 \pm 5$ \\
H-P25 & $6.1 \pm 0.1$ & $7.3 \pm 0.6$ & $36.5 \pm 0.6$ & $178 \pm 6$ \\
\hline
\end{tabular}
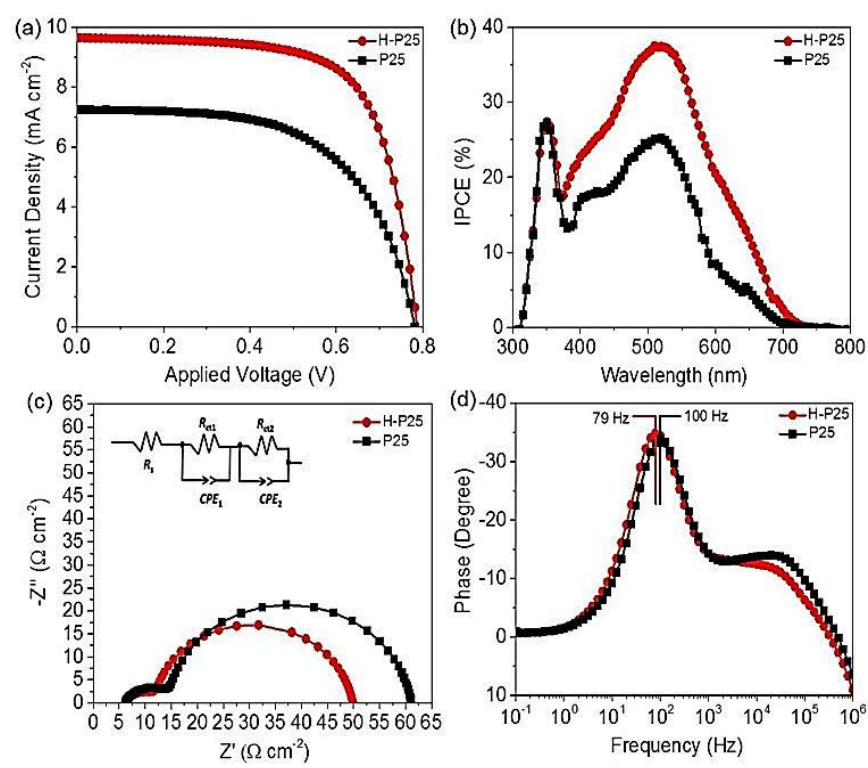

Figure 2: (a) J-V characterizations of DSC based on H-P25 and P25 photoanodes (thickness $(11.5 \pm 0.3)$ and area $\left(0.16 \mathrm{~cm}^{2}\right)$; (b) Incident photocurrent conversion efficiency (IPCE) ;Electrochemical impedance spectroscopy; (c) Nyquist plot; (d) Bode plot of devices based on H-P25 and P25 photoanodes.

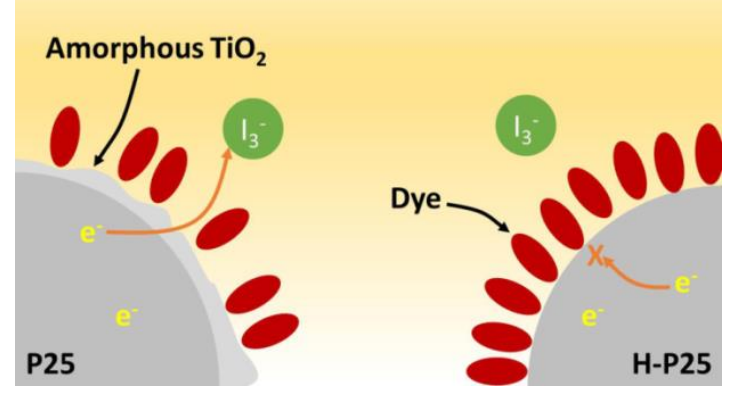

Scheme 1: Inhibition of electrons recombination at TiO2/13- interface by densely packed N719 layer (on clean total interfaces), and (irregularity spaced on P25 by amorphous).

Optical properties of P25 and H-P25 films including transmittance, diffuse reflection, absorbance and absorbance of dye, measured and reported in Figure $\mathrm{S} 3 \mathrm{a}-\mathrm{d}$, show minimal differences in the transmittance and diffuse reflection measurements while. This is in line with what would be expected, given the dye loading per unit area on both films were similar - the effects of higher dye packing density and lower surface area on H-P25 canceling one another out.

We have conducted all above measurements with devices based on photoanodes treated with $\mathrm{TiCl}_{4}$ for further 
investigation of the role of amorphous material. These devices also show the same trend for all measurements with overall efficiency $6.2 \pm 0.4 \%$ for $\mathrm{H}-\mathrm{P} 25$ treated with $\mathrm{TiCl}_{4}$ based devices, substantially higher than those of the P25 treated with $\mathrm{TiCl}_{4}$ based devices $4.3 \pm 0.3 \% \quad(\mathrm{~J}-\mathrm{V}$ and IPCE measurements, Table 3S, Table 4S and Figure 4S), (dye adsorption measurements, Table 5S, and Figure 5S), (EIS measurements, Table 6S, Figure $6 \mathrm{~S}$ and Figure S7). In addition we employed Stepped Light Intensity Modulated Photo Current and Voltage measurements (SLIM-PCV) in order to investigate the charge transport and recombination in $\mathrm{H}-\mathrm{P} 25$ and P25 based devices (Figure 8S). The SLIM measurements indicated that $\mathrm{H}-\mathrm{P} 25$ based device has longer life time which is well in agreement with EIS measurements while has higher trap density compared to P25 based devices. Hoverer, the difference in $J_{s c}$ for devices based on photoanodes without $\mathrm{TiCl}_{4}$ is a slightly higher than that treated with $\mathrm{TiCl}_{4}$ which can be attributed to the maintaining the higher dye loading on $\mathrm{H}$ P25 even without $\mathrm{TiCl}_{4}$ treatment resulting from higher surface roughness and the larger range of pore size distribution along with removing amorphous $\mathrm{TiO}_{2}$ (i.e. As $\mathrm{TiCl}_{4}$ treatment can be applied to reduce the morphology defects and reduce the charge recombination, $\mathrm{TiCl} 4$ treatment has higher impact on P25 devices performance than H-P25 (lower $J_{s c}$ than treated $\mathrm{TiCl}_{4}$ devices) indicating better performance of $\mathrm{H}-\mathrm{P} 25$ due to the lower recombination ( almost the same $J_{s c}$ compared to treated $\mathrm{TiCl}_{4}$ devices). The fill factor values are almost the same before and after $\mathrm{TiCl}_{4}$ treatment. The enhancement in $J_{s c}$ and $\mathrm{FF}$ can be resulted from removing the amorphous $\mathrm{TiO}_{2}$ and enhancing the morphology after special hydrothermal treatment

This study has investigated the effect of removing amorphous $\mathrm{TiO}_{2}$ in commercially available $\mathrm{TiO}_{2}$ (P25) on DSC performance. Amorphous $\mathrm{TiO}_{2}$ was dissolved and recrystallized to new anatase or rutile nanoparticles through selectively hydrothermal treatment. The efficiency of DSCs based on $\mathrm{H}$ P25 was enhanced by $44 \%$ compared to that based on untreated P25, due to a slightly increased $J_{s c}$, along with substantially better FF. The higher $J_{s c}$ was attributed to enhance light harvesting through higher dye loading on H-P25, in spite of having a lower specific surface area. This is attributed to the crystalline material having a more favorable surface construction for the dye to bind to. The enhancement in FF is attributed to substantially longer electron lifetimes, higher electron densities and suppressed recombination losses due to the removal of amorphous barriers and associated defect states. While it is seen that amorphous $\mathrm{TiO}_{2}$ affects negatively DSC performance, the PCE of DSC based on H-P25 is still low due to a high density of shallow traps, in spite of anatase and rutile being good materials for photoanodes in their own right. This study sheds light on an issue that has not been widely studied which can give more understanding to the role of amorphous $\mathrm{TiO}_{2}$ in the photovoltaic performance. Most researchers, ourselves included, have tended to ignore the role of amorphous $\mathrm{TiO}_{2}$ in the DSC photoanode. $\mathrm{P} 25$ persists as a control for many research gaps around the world, with quite variable performance. This may also impact the performance of other $\mathrm{TiO}_{2}$, used in $\mathrm{DSC}_{\mathrm{S}}$ and other devices, where the impact of amorphous content may go unnoticed.

\section{Conflicts of interest}

There are no conflicts to declare.

1. M. A. Lazar, S. Varghese and S. S. Nair, Catalysts, 2012, 2 572-601.

2. B. Ohtani, O. Prieto-Mahaney, D. Li and R. Abe, Journal of Photochemistry and Photobiology A: Chemistry, 2010, 216, 179-182.

3. Y. Ling, J. K. Cooper, Y. Yang, G. Wang, L. Munoz, H. Wang, J. Z. Zhang and Y. Li, Nano Energy, 2013, 2, 1373-1382.

4. J. Yu and W.-K. Ho, Materials Horizons, 2017.

5. D. Cahen, G. Hodes, M. Grätzel, J. F. Guillemoles and I. Riess, The Journal of Physical Chemistry B, 2000, 104, 2053-2059.

6. L. Kavan, M. Grätzel, S. Gilbert, C. Klemenz and H. Scheel, Journal of the American Chemical Society, 1996, 118, 6716-6723.

7. N.-G. Park, J. Van de Lagemaat and A. Frank, The Journal of Physical Chemistry B, 2000, 104, 8989-8994.

$8 . \quad$ J. Lin, Y.-U. Heo, A. Nattestad, Z. Sun, L. Wang, J. H. Kim and S. X. Dou, Scientific Reports, 2014, 4, 5769.

9. B. Prasai, B. Cai, M. K. Underwood, J. P. Lewis and D. Drabold, Journal of materials science, 2012, 47, 75157521.

10. K. Kaur and C. V. Singh, Energy Procedia, 2012, 29, $291-$ 299.

11. W. Q. Fang, X. H. Yang, H. Zhu, Z. Li, H. Zhao, X. Yao and H. G. Yang, Journal of Materials Chemistry, 2012, 22, 22082 22089.

12. C. Li, C. Koenigsmann, W. Ding, B. Rudshteyn, K. R. Yang, K. P. Regan, S. J. Konezny, V. S. Batista, G. W. Brudvig and C. A. Schmuttenmaer, Journal of the American Chemical Society, 2015, 137, 1520-1529.

13. C. Chen, G. A. Sewvandi, T. Kusunose, Y. Tanaka, S. Nakanishi and Q. Feng, CrystEngComm, 2014, 16, 88858895.

14. D. Wu, Z. Gao, F. Xu, J. Chang, S. Gao and K. Jiang, CrystEngComm, 2013, 15, 516-523.

15. A. Walker, H. Snaith, F. De Angelis and E. Da Como, Unconventional Thin Film Photovoltaics: RSC Energy and Environment Series, Royal Society of Chemistry, 2016

16. V. Johansson, L. Ellis-Gibbings, T. Clarke, M. Gorlov, G. G. Andersson and L. Kloo, Physical Chemistry Chemical Physics, 2014, 16, 711-718.

17. Y. Ide, N. Inami, H. Hattori, K. Saito, M. Sohmiya, N. Tsunoji, K. Komaguchi, T. Sano, Y. Bando and D. Golberg, Angewandte Chemie International Edition, 2016, 55, 3600-3605.

18. S. Kurian, P. Sudhagar, J. Lee, D. Song, W. Cho, S. Lee, Y. S. Kang and H. Jeon, Journal of Materials Chemistry A, 2013, 1, 4370-4375.

19. J. Lin, A. Nattestad, H. Yu, Y. Bai, L. Wang, S. X. Dou and J. H. Kim, Journal of Materials Chemistry A, 2014, 2, 89028909.

20. J. Bisquert, Journal of Electroanalytical Chemistry, 2010, 646, 43-51. 
Journal Name

21. J. Bisquert, A. Zaban, M. Greenshtein and I. Mora-Seró, Journal of the American Chemical Society, 2004, 126, 13550-13559.

22. Q. Wang, J.-E. Moser and M. Grätzel, The Journal of Physical Chemistry B, 2005, 109, 14945-14953.

23. R. Kern, R. Sastrawan, J. Ferber, R. Stangl and J. Luther, Electrochimica Acta, 2002, 47, 4213-4225.

24. H. H. Pham and L.-W. Wang, Physical Chemistry Chemical Physics, 2015, 17, 541-550. 